\title{
Pós-graduação de servidores públicos: percepções de egressos sobre os efeitos de uma especialização
}

Simone Guimarães Guerra Gama Barros

Fundação CAPES

Este artigo pretende verificar os efeitos do curso de especialização em Gestão Pública Municipal que integra o Sistema Universidade Aberta do Brasil. À luz das percepções dos egressos, buscou-se identificar as implicações efetivas do curso na vida pessoal, profissional e acadêmica dos participantes. Desenvolveu-se uma pesquisa descritiva e quantitativa, utilizando-se a técnica survey. A relevância do tema reside em avaliar a importância da capacitação em nível de pós-graduação de servidores públicos, que formam o aparelho burocrático estatal descrito por Max Weber. Em razão de burocracias estatais fortes e desenvolvidas contribuírem para o desenvolvimento dos países e de o novo modelo federalista brasileiro impor aos municípios novos desafios em termos de gestão e implementação de políticas públicas, a temática de capacitação de servidores públicos municipais se torna central para o Estado. Os resultados da pesquisa demonstraram que o curso teve desdobramentos relevantes na melhoria do desempenho profissional dos egressos que participaram do estudo.

Palavras-chave: burocracia, pós-graduação de servidores públicos, percepção de egressos

[Artigo recebido em 30 de junho de 2016. Aprovado em 03 de junho de 2018.] 
Graduate civil servants: perception of graduates on the practical effects of specialization.

This article aims to verify effects of the specialization course in Public City Management as a part of the Open University of Brazil. Observing alumni's perspectives, this paper sought to identify the positive effects the course brought to the participants' personal, professional and academic lives. Developing a descriptive and quantitative research, the technique used was the survey. The relevance lies in evaluating the importance of graduate-level training of civil servants, who form the state bureaucracy described by Max Weber. Considering that strong and developed state bureaucracies contribute to the development of countries and that the Brazilian federalist model imposes on municipalities, the issue of training municipal public servants becomes central to the State. The research results showed that the course had relevant developments in improving the professional performance of the alumnis who participated in the study.

Keywords: bureaucracy, graduate civil servants, graduates' perceptions

\section{Posgrado de empleados públicos: percepciones de graduados sobre los efectos prácticos de una especialización}

Este artículo pretende verificar los efectos del curso de especialización en Gestión Pública Municipal que integra la Universidad Abierta de Brasil. Sobre la base de las percepciones de los graduados, esta investigación ha tratado de identificar los efectos positivos que el curso tuvo en la vida personal, profesional y académica de los participantes. Fue desarrollada una investigación descriptiva y cuantitativa, y la técnica utilizada fue el "survey". La relevancia de la temática consiste en evaluar la importancia de la formación de posgrado de empleados públicos, que forman el aparato burocrático estatal descrito por Max Weber. Al considerar que burocracias estatales fuertes y desarrolladas contribuyen al desarrollo de los países y que el modelo federalista brasileño impone a los municipios nuevos desafíos para la gestión e implementación de políticas públicas, la temática de capacitación de empleados públicos municipales se hace central para el Estado. Los resultados de la investigación demostraron que el curso tuvo desdoblamientos relevantes en la mejoría del desempeño profesional de los egresos que participaron del estudio.

Palabras clave: burocracia, posgrado de empleados públicos, percepción de graduados 


\section{Contextualização}

Considerando a necessidade latente de capacitação de servidores públicos municipais, bem como a finalidade do curso de GPM que busca contribuir para aumentar a capacidade técnica de tais servidores públicos, esta pesquisa propõese a identificar quais as percepções que os egressos do curso de GPM/PNAP/UAB possuem a respeito da qualificação obtida e a melhoria do desempenho de suas funções como servidor público municipal.

Assim, os objetivos da pesquisa são: a) verificar se os egressos percebem que o curso que fizeram contribuiu de forma inequívoca para sua qualificação técnica, repercutindo positivamente na qualificação dos quadros técnicos dos órgãos públicos municipais; b) observar se os egressos se sentem mais bem preparados para desempenhar suas funções como servidores públicos; c) verificar se os egressos notam que outros profissionais percebem e valorizam o conhecimento que foi obtido por eles no curso; d) verificar se houve crescimento profissional e crescimento acadêmico efetivo após a conclusão do curso; e) verificar se os egressos que são servidores públicos possuem incentivos relacionados aos seus planos de carreira para participarem de capacitações; f) fornecer subsídios, por meio de informações fornecidas pelos egressos, para os gestores do programa e para os acadêmicos envolvidos na concepção e implementação do curso.

O Estado tem sofrido cada vez mais pressão por parte da sociedade no sentido de fornecer serviços públicos com mais qualidade e quantidade. Dessa forma, precisa contar com servidores públicos bem capacitados, que sejam capazes de contribuir de forma efetiva para a formulação, desenho e implementação das políticas públicas.

No Brasil, a Constituição Federal de 1988 (CF/88) inovou em termos de direito público e administração pública ao reconhecer o município como ente federal, em pé de igualdade com a União e os Estados (BRASIL, 1988). Assim, os municípios foram dotados de atribuições novas, aumentando consideravelmente seus deveres em termos de políticas públicas. No entanto, a grande maioria dos municípios possui capacidade administrativa e técnica limitadas, prejudicando seu desempenho no cumprimento de suas funções constitucionais (LASSANCE, 2013).

Em razão disso, os municípios necessitam capacitar seus quadros de pessoal, e uma das formas de atingir o objetivo de ampliação da qualidade do serviço público pode ser efetuada por meio da pós-graduação. Assim, o Governo Federal oferece um curso em nível de especialização que visa capacitar gestores públicos municipais: Gestão Pública Municipal (GPM). A seguir, são explicadas as origens desse curso e seus objetivos específicos. 


\section{O curso de especialização em Gestão Pública Municipal}

O curso de especialização em Gestão Pública Municipal faz parte do Programa Nacional de Formação em Administração Pública (Pnap), que por sua vez integra o Sistema Universidade Aberta do Brasil (UAB). Este se trata de uma ação pública criada no âmbito do Ministério da Educação (MEC) em 2006, visando, dentre outros objetivos, à formação de profissionais que atuam na área de gestão e administração pública, por meio de cursos ofertados na modalidade a distância (BRASIL, 2006).

Atentando-se para o objetivo destacado acima, os gestores da UAB, atualmente sob a responsabilidade da Coordenação Pública de Aperfeiçoamento de Pessoal de Nível Superior (Capes), criaram o Pnap em 2009 contando com quatro cursos: Bacharelado em Administração Pública, Especialização em Gestão Pública, Especialização em Gestão Pública Municipal e Especialização em Gestão em Saúde. Esses cursos buscam contribuir para a melhoria da gestão das atividades desempenhadas pelo Estado brasileiro em todos os níveis (COORDENAÇÃo DE Aperfeiçoamento de Pessoal de Nível SuPerior - Capes, 2009).

De forma geral, o funcionamento dos cursos do sistema UAB segue a seguinte dinâmica: a Capes possui os recursos federais destinados a esses cursos e define regras gerais de participação no programa, às quais as Instituições Públicas de Ensino Superior (Ipes) e polos de apoio presencial se sujeitam.

No caso dos cursos do Pnap, os cursos são nacionais, ou seja, possuem um projeto pedagógico unificado, criado e desenhado por comissão de especialistas da área (CAPES, 2013). As Ipes que desejam ofertar tais cursos aderem ao projeto pedagógico único e indicam os polos nos quais desejam atuar, sendo vetada a oferta de um mesmo curso por duas IPES no mesmo polo.

A dinâmica de oferta dos cursos do Pnap demonstra a capilaridade que tais cursos possuem, podendo ser cursados por servidores de pequenos municípios, inclusive aqueles com menores índices de desenvolvimento humano municipal (IDHM). Os cursos de pós-graduação destinam-se a portadores de diploma de nível superior que já são servidores públicos ou que almejam ser. Dessa forma, os cursos não são oferecidos estritamente para servidores públicos, já que são ofertados por instituições públicas. Porém, espera-se, principalmente em nível de especialização, que os alunos sejam servidores públicos atuantes em esfera e setor correlacionados ao curso: ou seja, que os alunos de GPM sejam servidores públicos municipais, buscando formação específica e diferenciada para cumprir suas atribuições. 


\section{Referencial teórico}

Max Weber discutiu em suas obras aspectos relevantes sobre a organização do Estado. O conceito de poder tem uma posição chave nessa discussão e pode ser definido como sendo a capacidade de o ente impor sua vontade, ainda que necessite o uso de força para tal (WEBER, 2002). Complementar à ideia de poder, tem-se o conceito de dominação, que implica na aceitação e obediência por parte do dominado pautado na legitimidade que atribui ao dominador. $A$ concordância por parte do dominado de ter o poder exercido sobre ele tem aspectos internos e externos, sendo que uma forma de dominação pelo aspecto interno é a dominação racional-legal.

A dominação racional-legal está pautada na legalidade, ou seja, leis e normas que estão circunscritas a um modelo racional, que cria competência objetiva e obediência às regras fixadas nos estatutos (WEBER, 2004). A burocracia, então, é instrumento de efetividade da dominação racional-legal e suas características giram em torno dos conceitos de formalidade, impessoalidade, profissionalização, rigidez e hierarquia. Motta (2008, p. 29-30) conceitua a burocracia de Weber como sendo um "aparato administrativo que sustenta a dominação legal ou racional-legal (...). Crentes nas leis e na ordem legal e tidos como burocratas, funcionários que o integram têm posições e relações definidas por regras impessoais".

No sistema burocrático, as normas regem os atos dos servidores que, em algum nível, possuem autoridade burocrática advinda de um regulamento ou norma administrativa que determina as suas funções, direitos e deveres. Para exercer essas funções, os servidores públicos necessitam de treinamento especializado, atendendo ao sistema meritocrático (WEBER, 2004).

Weber aponta que o desenvolvimento da burocracia ocorreu em todos os setores da sociedade em resposta às necessidades do Estado moderno e da economia capitalista: "a razão decisiva do avanço da organização burocrática sempre foi sua superioridade técnica sobre qualquer outra forma" (WEBER, 2004, p. 212). A burocracia, então, teria propiciado a organização dos Estados nacionais modernos após a Idade Média, sendo àquela e seu processo de racionalização democrática essenciais para o desenvolvimento dos Estados (WEBER, 2004).

Dessa forma, o progresso do funcionalismo implica o progresso do próprio Estado, sendo que o treinamento especializado é considerado uma das formas de aprimorar a burocracia. Tem-se, então, um círculo virtuoso entre burocracia mais bem especializada (aliada a outras questões como planos de carreira, bons salários etc.) e Estado mais desenvolvido. Portanto, a capacitação da burocracia contribui para a racionalização desta, sendo necessário que seja dada atenção especial a essa necessidade de especialização do corpo de funcionários burocráticos. 


\section{Burocracia, capacitação e desenvolvimento: um paralelo histórico- conceitual}

Atualmente, muitos autores defendem haver correlação positiva entre o desempenho da burocracia estatal de um país e o seu crescimento econômico. Publicações que analisaram o caso da Coreia e de Taiwan reforçam esse argumento, ao relacionar o acelerado e bem-sucedido processo de industrialização dos tigres asiáticos às suas burocracias bem preparadas (EVANS; RAUCH, 2014). Por sua vez, Bersh, Praça e Taylor (2013), ao estudarem as instituições federais brasileiras, concluíram que tanto na dimensão capacidade quanto na dimensão autonomia a burocracia weberiana é essencial para resultados positivos das políticas governamentais.

Rubens Ricupero (2015) corrobora essa ideia ao afirmar que é praticamente um consenso, em nível internacional, que para um país se desenvolver é imprescindível uma burocracia estatal muito bem qualificada, capaz de gerir e implementar as políticas públicas e todas as demandas da sociedade que o Estado deve prover. Assim, a capacitação de servidores públicos toma uma posição de centralidade na discussão sobre o Estado e suas atribuições, pois, quer seja o Estado liberal ou intervencionista, para ser eficiente necessita ter funcionários com alto nível de qualificação. Em estudo recente, Batista (2015) buscou analisar se a qualidade da burocracia local teria relação com uma maior qualidade da implementação das políticas sociais descentralizadas, já que boa parte das políticas sociais são formuladas em nível federal e implementadas pelos municípios, constatando que "há indícios de que a qualidade da burocracia está associada à melhor gestão de recursos de transferências federais e, por conseguinte, à entrega de melhores serviços para a população" (BATISTA, 2015, p. 366).

Assim, considerando "que as burocracias estatais caracterizadas pelo recrutamento meritocrático e por carreiras previsíveis e gratificantes estão associadas a maiores taxas de crescimento" (EVANS; RAUCH, 2014, p. 428) e também ao bem-estar da sociedade em geral, a capacitação de servidores se configura não somente como assunto administrativo e gerencial, mas também de relevância política e econômica.

Para Lopez (2015), as políticas públicas têm seu escopo definido em meio às disputas entre política e burocracia, sendo a burocracia a responsável por gerir as políticas públicas e entregar aos cidadãos os bens e serviços públicos. Logo, importa saber quem são as pessoas ocupantes de cargos públicos e quão qualificadas elas estão para servir ao bem comum.

A forma de ingresso em cargos públicos no Brasil já se deu de várias formas distintas ao longo do tempo. Durante o Brasil colônia, "as nomeações eram uma 
forma de aliciamento ou de retribuição de favores, sem quaisquer indícios do sistema de mérito" (INStituto de Pesquisa Econômica AplicadA, 2010, p. 317). Ainda assim, como episódio isolado, nesse período ocorreu o primeiro concurso público de que se tem registro no Brasil. No ano de 1759, dezenove professores foram selecionados para o exercício no magistério na Bahia (IPEA, 2010).

Já no Brasil Império, os cargos públicos continuavam a ser providos sem qualquer tipo de seleção, mas isso não significa que as pessoas que o ocupavam eram despreparadas; pelo contrário, a maioria dos funcionários públicos eram ou membros da aristocracia brasileira, com formação superior no exterior (CERVo, 1981); ou talentos individuais, que eram cooptados (mobilidade social) a trabalhar em prol de um partido ou de outro (IPEA, 2010).

Durante o período comumente chamado de Primeira República, deu-se continuidade à lógica imperial de ter um pequeno grupo de funcionários públicos de elite, bem remunerado e que gozava de grande prestígio social. As tentativas de concurso público eram poucas e restritas às grandes cidades, como Rio de Janeiro e São Paulo (IPEA, 2010).

Com o advento do Governo de Getúlio Vargas, a administração pública brasileira passou por sua primeira reforma, capitaneada pelo Departamento Administrativo do Serviço Público (DASP) que, dentre muitas medidas, adotou o concurso público como forma essencial de provimento dos cargos públicos, estabelecendo um sistema meritocrático. No entanto, o instituto do concurso público não se tornou padrão nas repartições públicas, pois não tinha o apoio da opinião pública como um todo (IPEA, 2010). Dado o histórico do país e de como se foram alicerçando as relações sociais, o tratamento da coisa pública como sendo privada por parte dos governantes não era considerado ato tão ofensivo ou inescrupuloso.

Durante outra ditadura, desta vez militar, ocorreu uma segunda reforma da administração pública. Esta não fortaleceu o concurso público, mas criou outras possibilidades de contratação de pessoal, visando atender às demandas das diversas fundações, autarquias, empresas públicas e sociedades de economia mista que foram criadas. Para contrabalancear as contratações empreguistas, baseadas em favores pessoais:

A solução fora criar "bolsões de eficiência" na área da ação econômica estatal. Ficavam, assim, as estatais e congêneres dotadas de recursos humanos com mais capacidade técnica e conhecimento especializado. Nelas, a admissão dependia de esquemas de averiguação de aptidões, via concurso ou à maneira das contratações no setor privado. (IPEA, 2010 p. 354). 
Por sua vez, a Constituição de 1988 estabeleceu o concurso público como sendo o único meio de ingressar em cargo público efetivo, estabelecendo o princípio da seleção universal e meritocrática. Os que passam em determinado concurso público ingressam na carreira pública com possibilidade de adquirir estabilidade no cargo. Todos esses aspectos já eram defendidos por Weber como necessários para o fortalecimento da burocracia estatal.

Anos depois, durante a terceira reforma administrativa ocorrida em 1995 por meio do Plano Diretor da Reforma do Estado (PDRAE) houve o fortalecimento das carreiras de Estado, a abertura de vários concursos públicos e a revitalização das capacitações de servidores feitas pela Escola Nacional de Administração Pública, Enap, criada com a finalidade de capacitar os servidores públicos federais (ABRúcıo, 2007). De fato, a capacitação constante dos servidores deve ser buscada, pois durante a carreira do servidor surgirão novas demandas da sociedade e novos conhecimentos e habilidades disponíveis serão necessários para realizarem suas funções de forma cada vez mais eficiente. Os funcionários públicos precisam possuir incentivos e meios de se capacitarem, fortalecendo a burocracia brasileira cada vez mais, com vistas à melhoria dos bens e serviços ofertados pelo Estado.

\section{Federalismo brasileiro: os municípios e seus servidores}

Em relação ao federalismo brasileiro, após a promulgação da $\mathrm{CF} / 88$, não havia limitações legais quanto à criação de municípios, ocorrendo uma geração desenfreada de novos municípios que buscavam receber transferências do Governo Federal e dos Estados (LASSANCE, 2013). Isso contribuiu para a atual discrepância entre os entes federados, em termos de tamanho e condições fiscais, econômicas e administrativas. No entanto, as atribuições constitucionais não levam em conta tais aspectos; assim, municípios grandes ou minúsculos possuem a mesma obrigação de prover educação e saúde, cuidar de todas as questões urbanísticas e rurais do município, além de recolher os impostos que são de sua competência (CARVALHO, 2011).

Tal realidade contribuiu para o aumento da quantidade de servidores públicos municipais nos últimos anos. De acordo com dados da Pesquisa de Informações Municipais (Munic) publicada pelo Instituto Brasileiro de Geografia e Estatística (2015), cresce a cada ano a quantidade de servidores públicos civis (estatutários e celetistas) em relação ao tamanho total da população: "em 2001, a população brasileira somava 172,4 milhões de habitantes e a proporção de servidores municipais era de 2,2\%. Em 2014, esta relação subiu para 3,2\%, quando a população atingia 202,8 milhões de habitantes" (INSTITUTO BRASILEIRO DE Geografia e Estatística, 2015, p. 16). 
Muitos municípios são extremamente dependentes do Fundo de Participação dos Municípios (FPM). Como alguns municípios praticamente não possuem receitas próprias, para eles o impacto financeiro de sua estrutura administrativa se torna maior relativamente, pois possuem poucos recursos, dificultando pagar bons salários para os servidores públicos, favorecendo, em muitos casos, a contratação de terceirizados. Pela razão exposta acima, bem como pela função de indutora nacional de políticas públicas, a União possui, através de seus ministérios temáticos, uma infinidade de programas que visam auxiliar os municípios na consecução de suas atribuições. Ocorre que, muitas vezes, há municípios que não são beneficiados por tais programas por não terem ao menos servidores públicos capacitados e qualificados que conheçam tais programas, muito menos que, além de conhecer, saibam como cumprir efetivamente os requisitos para receber as transferências ou participar de convênios.

De acordo com Carvalho (2011, p. 306), "muito do que ocorre no emprego público municipal se deve às políticas públicas de âmbito nacional. A questão do emprego público no município ganha, assim, dimensão nacional". Por um longo período de tempo privilegiou-se a capacitação de servidores públicos da área de economia e federais, sendo recente o entendimento de que todos os servidores devem ser alvo de capacitações, especialmente os da esfera municipal. Faz-se necessário, então, que haja políticas públicas nacionais voltadas à capacitação de servidores públicos municipais e estaduais para que estes consigam viabilizar e melhorar a qualidade das políticas públicas que chegam até suas localidades.

Quando uma empresa privada investe na capacitação de seus funcionários, ela espera obter retornos positivos no sentido de aumentar seus lucros por meio da melhoria do desempenho dos funcionários. No caso do serviço público, o retorno da capacitação vem em forma de melhoria dos serviços prestados ao cidadão e no funcionamento da máquina pública em geral.

Dessa forma, o Governo Federal tem-se empenhando em promover a qualificação, não só de seus quadros de pessoal, mas também dos servidores estaduais e municipais, mesmo porque a descentralização trazida pela CF/88 depende de uma burocracia forte em todas as esferas de governo; se não for assim, a descentralização não desembocará em melhoria dos serviços públicos prestados.

No entanto, apesar dos esforços que têm sido realizados no sentido de proporcionar oportunidades de capacitação em nível de pós-graduação, estudos que busquem medir efeitos de tais cursos são escassos na literatura nacional e internacional (PILATI; PORTO; SILVINO, 2007), possivelmente, em parte, pela dificuldade em mensurar os efeitos das ações de capacitação formal. Medir de forma objetiva se o servidor público cumpre suas atribuições com melhor qualidade 
em razão de uma capacitação feita é algo extremamente complexo. Entre as razões encontram-se a diversidade e a natureza das atribuições dos servidores. A maior parte dos editais de concurso público, por exemplo, estabelece de forma genérica as atribuições dos servidores, sendo que estas variam bastante de órgão para órgão e mesmo dentro de cada setor em um mesmo órgão.

Uma das perspectivas que se pode adotar ao avaliar uma ação pública é a de percepção de resultados por parte dos beneficiários da política pública, isto é, avaliar quais variáveis de interesse sofreram alteração após a execução do programa, assim avaliando se os efeitos de um programa de capacitação sobre o desempenho profissional do servidor é tarefa árdua, ainda mais se tratando de múltiplos órgãos e em múltiplos municípios. Importante, então, lembrar que, ao avaliar as políticas públicas, devem-se considerar as especificidades de cada uma. No caso desta avaliação, optou-se por se valer da ótica do próprio egresso, verificando as percepções positivas, negativas e de efetividade do curso. Assim, obtendo-se a visão subjetiva de cada um, pode-se comparar objetivamente se os beneficiários da política pública consideram que a ação de capacitação cumpriu seus objetivos iniciais.

\section{Metodologia}

O processo investigativo científico deste estudo utilizou como base a abordagem quantitativa, pois foi construída uma base de dados com as respostas dos egressos através de survey (técnica). Por meio de uma amostra, obtiveram-se dados que representam a situação profissional do egresso após finalizar o curso. A partir desses dados foram feitas análises das dinâmicas relacionadas às variáveis estudadas, buscando aprofundar as questões tratadas e oferecer interpretações para os resultados obtidos.

Quanto à natureza, essa pesquisa é aplicada pois "objetiva gerar conhecimentos para aplicação prática, dirigidos à solução de problemas específicos. Envolve verdades e interesses locais" (GERHARDT; SILVEIRA, 2009, p. 35). Esta pesquisa procura contribuir para o debate a respeito de pertinência e resultados práticos que o curso de especialização em GPM tem tido no desempenho profissional dos que o cursam.

Quanto ao objetivo, o estudo enquadra-se na classe de pesquisa descritiva e explicativa. Descritiva porque procura descrever os fatos relevantes encontrados com a aplicação do survey; explicativa porque pretende-se analisar as relações entre os fenômenos encontrados, fornecendo interpretações à luz das teorias apresentadas. 


\section{Aplicação e construção do questionário}

A base de dados inicial foi obtida através do Sistema de Informações da Universidade Aberta do Brasil (SisUAB), sendo as informações disponíveis: os dados cadastrais básicos (nome, CPF, gênero, e-mail, data de nascimento, endereço e telefone) e os dados a respeito do curso que realizou (IPES ofertante, polo de apoio presencial, ano de início e conclusão do curso). O envio da pesquisa foi realizado por mensagem eletrônica; no entanto, $25 \%$ dos egressos não possuíam e-mail cadastrado no SisUAB, o que inviabilizou o contato com essas pessoas. Por essa razão, o questionário não pôde ser enviado aos egressos do curso em sua totalidade (6.577). O número de egressos com e-mail informado totalizou 4.908 pessoas e, por fim, 1352 egressos concluíram o questionário com êxito, ou seja, 20,7\% de todos os alunos que se formaram até dezembro de 2015 participaram da pesquisa.

A pesquisa foi gerenciada e aplicada por meio do software LimeSurvey e contou com 24 perguntas, em variados formatos, ainda que todas fechadas (BARROS, 2016). As perguntas foram agrupadas conforme suas finalidades, resultando em cinco blocos: identificação do curso, perfil do egresso, formação acadêmica, atuação profissional, avaliação do curso e avaliação dos efeitos do curso.

O bloco das perguntas sobre avaliação dos efeitos do curso se configurou como o cerne de todo o questionário. Isso porque ele continha as perguntas cruciais relativas à pesquisa, que possibilitaram saber se houve efeitos práticos positivos em termos pessoais, profissionais e acadêmicos relacionados ao curso. As perguntas integrantes dos outros blocos ajudaram a entender as razões das respostas dadas no último bloco.

Considerando, então, as possíveis relações entre as respostas das perguntas que viabilizam a identificação dos efeitos percebidos pelos alunos concluintes do curso com as demais perguntas do questionário, como estratégia de análise, definiramse cinco dimensões de resultados que foram tratadas como nossas variáveis dependentes, ou seja, buscou-se saber como essas dimensões foram afetadas após a conclusão do curso. As dimensões foram: desempenho profissional, satisfação pessoal, crescimento profissional e crescimento acadêmico.

Em cada uma dessas dimensões, considerou-se haver variáveis que poderiam ter efeito sobre elas - as chamadas variáveis intervenientes - que eram: sexo; faixa etária; renda familiar; município em que trabalha; área do curso de graduação; possuir escolaridade em nível de pós-graduação antes de iniciar o curso; ser servidor público quando iniciou o curso; e qualidade do curso (considerada em três aspectos principais: qualidade substantiva, qualidade da estrutura do polo de apoio presencial e qualidade das estruturas de apoio ao curso). 
Importante salientar que a escolha das variáveis intervenientes foi baseada em hipóteses a respeito de possíveis relações destas com as variáveis dependentes, para, posteriormente, considerando a análise dos dados obtidos, confirmar ou refutar tais hipóteses. Abaixo a síntese dessas hipóteses (Quadro 1):

Em suma, o questionário foi constituído de uma série de perguntas diretas a respeito das variáveis dependentes, para que os respondentes se posicionassem a respeito das afirmativas propostas. Também havia uma série de perguntas relativas às variáveis intervenientes, nas quais eles não tinham que avaliar nada, apenas responder com objetividade algum dado concreto, como sua idade ou a cidade em que mora.

\section{Apresentação e discussão de resultados}

Os principais resultados referentes às cinco dimensões de análises definidas serão demonstrados por meio da frequência das respostas, bem como de análise bivariada, ou seja, cruzamento entre uma variável dependente e outra interveniente (na maioria dos casos as variáveis em questão são qualitativas) para possibilitarem a verificação de associação ou não entre elas.

A melhoria do desempenho profissional (dimensão 1 ) foi avaliada por meio da questão $\mathrm{n}^{\circ} 18$, que se tratava da seguinte afirmação: "Após ter participado do curso Gestão Pública Municipal, adquiri novos conhecimentos, habilidades ou competências que melhoraram meu desempenho no trabalho". Após ler a afirmação, o candidato tinha que expressar seu grau de concordância com a afirmativa por meio das opções: "Concordo Totalmente; Concordo mais do que discordo; Discordo mais do que concordo; Discordo Totalmente; não tenho opinião".

Observando-se o Gráfico abaixo (Gráfico 1 ) se tem que 64,28\% dos egressos concordaram totalmente com a afirmação, enquanto 30,55\% concordaram com ressalvas. De todo modo, $94,83 \%$ dos egressos perceberam um impacto positivo no seu desempenho profissional de um modo prático. Já $4 \%$ dos egressos tiveram uma percepção negativa, discordando totalmente da afirmação ou discordando mais que concordando. O alto grau de concordância revelado, porém, sustenta a afirmação de que, na opinião dos egressos, o curso contribuiu para a melhoria do seu desempenho profissional. 


\section{Grafico 1 - Melhoria do Desempenho Profissional}

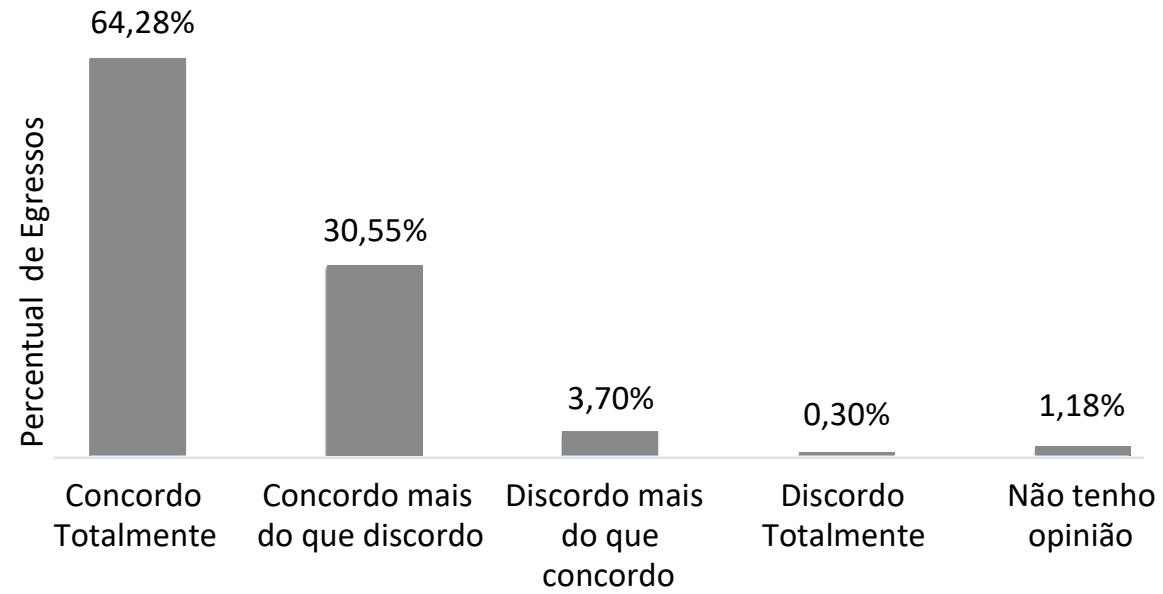

Fonte: BARROS, 2016

Em relação aos elementos que poderiam estar associados ou não a essas percepções, a análise bivariada dessa dimensão com as variáveis intervenientes indicou que a qualidade do curso, das estruturas de apoio e do polo são fatores que contribuem para explicar por que uma parte (reduzida) dos egressos não concordou com a percepção de melhorias sobre o seu desempenho profissional após o curso. Isso porque aqueles egressos que avaliaram melhor a qualidade do curso são também os que afirmaram ter observado melhoria no seu desempenho profissional. De maneira análoga, a pequena parcela dos egressos que declarou não ter percebido melhoria no seu desempenho profissional apresentou maior tendência a avaliar a qualidade do curso negativamente.

De acordo com Freitas et al. (2013), não é tarefa simples medir a produtividade do servidor, pois esta envolve fatores complexos e subjetivos. No caso deste trabalho, dada a multiplicidade de órgãos, municípios e funções ocupadas, considerou-se ser a percepção do egresso um parâmetro útil por ser uma medida não influenciada pela diferença entre as atribuições dos egressos. Adicionalmente, visto que a pesquisa manteve a identidade dos respondentes em sigilo, estes não teriam razões para prestar informações falsas. Outro ponto que reafirma a confiabilidade nas respostas é que, nas perguntas relativas à percepção, os respondentes tinham a opção de marcar que não sabiam avaliar a situação descrita na pergunta, evitando, assim, respostas inseguras ou de pessoas que não compreenderam o seu significado. 
Quanto à dimensão de satisfação pessoal (segunda dimensão), essa satisfação pessoal possui duas facetas: a primeira se refere ao egresso se sentir, independentemente da opinião de outros, mais confiante e seguro com o conhecimento adquirido no curso. A segunda refere-se ao egresso perceber que seus colegas de trabalho e superiores possuem maior respeito e reconhecem a capacitação feita como tendo aspectos positivos.

Para poder observar e diferenciar esses dois aspectos, foram feitas as perguntas P19 e P20, respectivamente: "Após ter participado do curso Gestão Pública Municipal, sinto-me mais confiante e seguro para debater questões relativas à gestão pública com meus colegas e superiores no ambiente de trabalho" (P19); "Percebo que meus colegas de trabalho e meus superiores me ouvem, admiram e respeitam mais minhas opiniões e decisões após ter feito o curso Gestão Pública Municipal" (P20). Como resposta, o egresso podia escolher, dentro de uma escala de concordância, a resposta que melhor se encaixava na sua situação: "Concordo Totalmente; Concordo mais do que discordo; Discordo mais do que concordo; Discordo Totalmente; não tenho opinião".

De acordo com o Gráfico $\mathrm{n}^{\circ} 2$, a maior parte dos egressos respondeu que concorda totalmente que a confiança em si mesmo aumentou após o curso $(63,31 \%)$, sendo que $31,43 \%$ também afirmou concordar mais do que discordar com essa afirmação, perfazendo um total de $94,74 \%$ de respondentes que identificaram melhoria de sua confiança a respeito de assuntos concernentes à gestão pública municipal.

\section{Grafico 2 - Aumento da confiança em si - pós GPM}

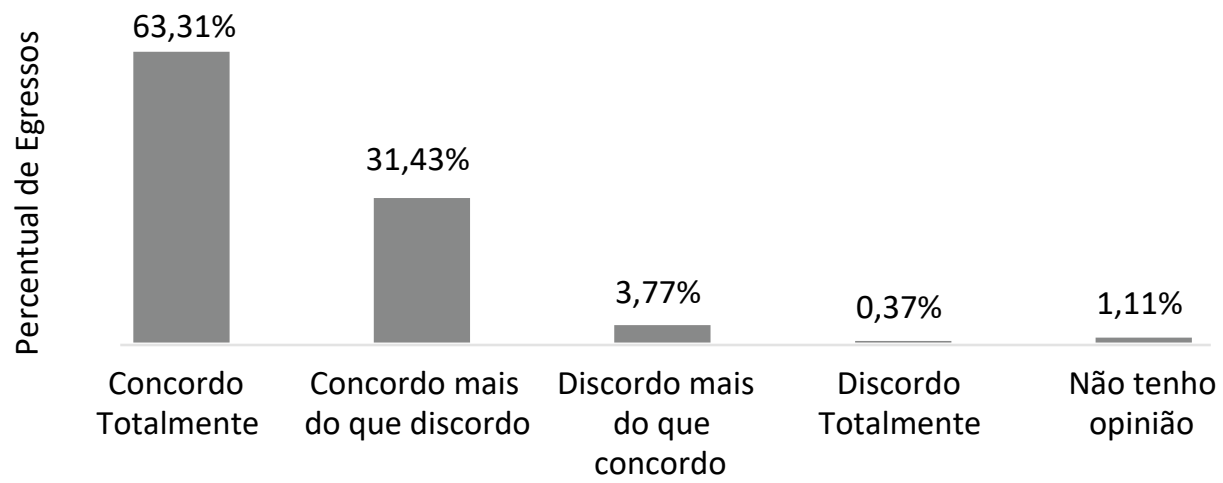

Fonte: BARROS, 2016 
Os números foram menos animadores no tocante ao reconhecimento de terceiros e consequente elevação da estima do egresso no grupo social profissional no qual está inserido, já que o grupo de pessoas que concordaram totalmente com a afirmação não foi a maioria, além do que quase $14 \%$ dos respondentes tiveram uma resposta negativa a respeito (Gráfico 3). Portanto, pode-se concluir que, em relação à satisfação pessoal, a maior parte dos egressos respondentes possui um contentamento pessoal com o curso, mas nem sempre se sentem reconhecidos por terceiros em relação ao conhecimento adquirido.

\section{Grafico 3 - Reconhecimento no ambiente de trabalho}

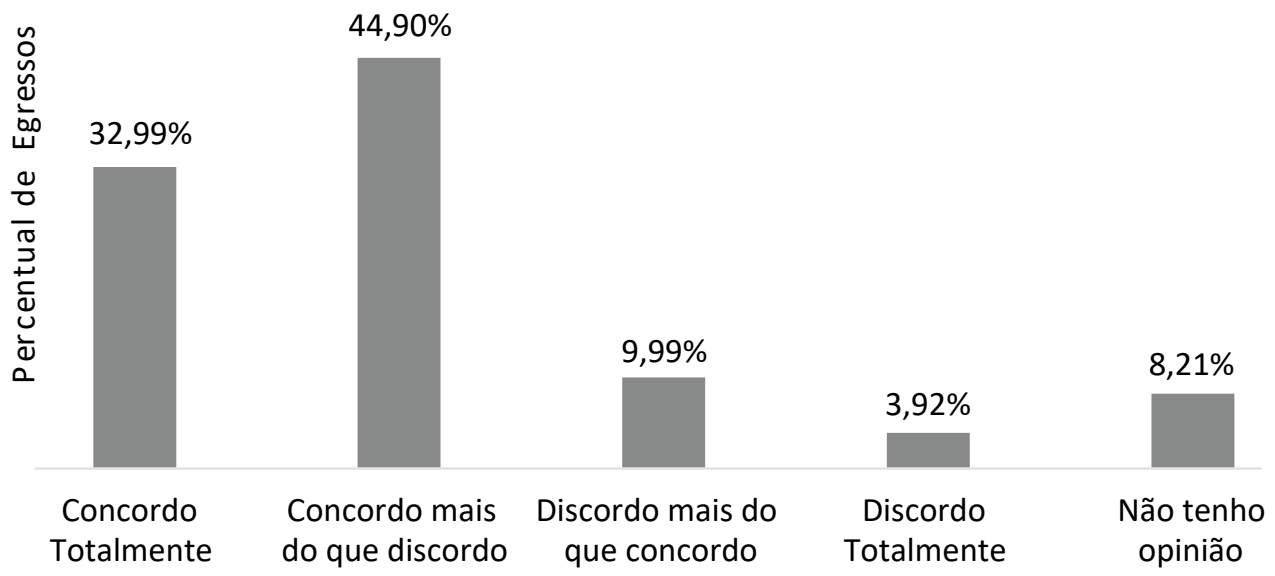

Fonte: BARROS, 2016

Quanto à avaliação de que fatores poderiam influenciar essa percepção dos egressos em relação à confiança em si mesmo e à percepção que os outros possuem deles, foi observado que, quanto maior a qualidade do curso, maior a satisfação pessoal.

Notou-se também associação entre a renda familiar e o aspecto da dimensão de satisfação pessoal relacionado ao reconhecimento de terceiros, pois, quanto maior a faixa de renda, menor a proporção de egressos que concordam que obtiveram reconhecimento de terceiros; de modo similar, quanto menor a faixa de renda, maior a proporção dos egressos que perceberam ter tido aumento de reconhecimento de terceiros. Ao contrário, o outro aspecto da dimensão pessoal, a elevação da confiança em si, demonstrou não ter associação com a faixa de renda, pois as proporções de egressos que concordam totalmente em cada faixa de renda são similares, não havendo, então, relação existente. Portanto, não podemos concluir que há associação entre a dimensão de satisfação pessoal como um todo com a variável faixa de renda, mas, sim, que esta possui relação apenas com a percepção de reconhecimento de terceiros e não com a elevação de 
confiança em si por parte do egresso. Isso quer dizer que os egressos adquiriram no curso conhecimentos, capacidades e habilidades que Ihes permitem ter uma posição mais ativa e menos passiva no trabalho, já que se sentem seguros quanto a debates com colegas e superiores sobre questões relativas à gestão pública. Assim, saem de uma posição de apenas executores, passando à de profissionais que conseguem refletir sobre problemáticas a respeito de políticas públicas, podendo contribuir com mais propriedade em face aos desafios enfrentados pelos órgãos em que trabalham. A realidade é que a forma como a própria pessoa e os que trabalham com ela enxergam o aprendizado obtido na pós-graduação tem muita influência sobre o desempenho do profissional, pois a profissão escolhida não é somente meio de sustento para as pessoas, mas tem significado social (WEBER, 1982). Dessa forma, o fato de a maior parte dos egressos se sentir mais confiante em seus conhecimentos a respeito de gestão pública, e notar que terceiros também percebem isso, são fatores que contam positivamente para o próprio fortalecimento da burocracia estatal. Juntamente com os demais incentivos que o Estado necessita prover para os servidores, essa estima valorizada contribui para a permanência do servidor no cargo.

Quanto à dimensão relativa ao crescimento profissional, o objetivo das perguntas era obter dados de fatos objetivos a respeito do crescimento profissional dos egressos. Para tanto, três perguntas se referiam diretamente a conquistas obtidas no meio profissional do serviço público. Assim, as perguntas tratavam de saber se o egresso passou em algum concurso público, se ele assumiu alguma função comissionada ou foi cedido a outro órgão público (sempre em razão dos conhecimentos adquiridos no curso).

De acordo com o Gráfico 4, 22,56\% dos egressos foram aprovados em algum concurso público após cursarem GPM, número que em termos absolutos totaliza 305 pessoas. Destas, $52,79 \%$ para concursos municipais e $69,18 \%$ para cargos com vínculo de estatutário (Gráfico 5). Esses números demonstram bons resultados do curso, considerando que o objetivo do curso é capacitar os servidores públicos municipais. 0 fato de a maioria estar no serviço municipal reforça o caráter direcionado da pós-graduação. Não menos importante é a constatação de a maior parte dos servidores serem estatutários (Gráfico 6), pois sinaliza o investimento assertivo no sentido de capacitação de pessoas que, ou já são, ou provavelmente serão estáveis no serviço público, integrando e fortalecendo o corpo burocrático a ser continuamente capacitado. Quanto maior o percentual de servidores estáveis em nossos órgãos públicos, maior o fortalecimento da burocracia dentro da concepção racional-legal. O fortalecimento da burocracia estatal desemboca também na continuidade das políticas públicas, sendo o 
estatuto da estabilidade no serviço público mais um fator que contribui para a permanência do servidor em seu cargo.

Grafico 4 - Passou em concurso público - pós GPM

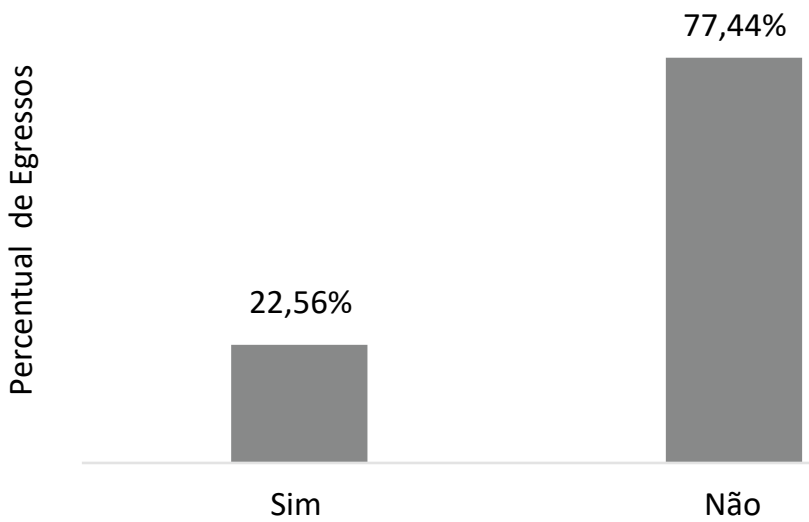

Fonte: BARROS, 2016

Grafico 5 - Esferas de governo dos concursos públicos que os egressos foram aprovados - pós GPM

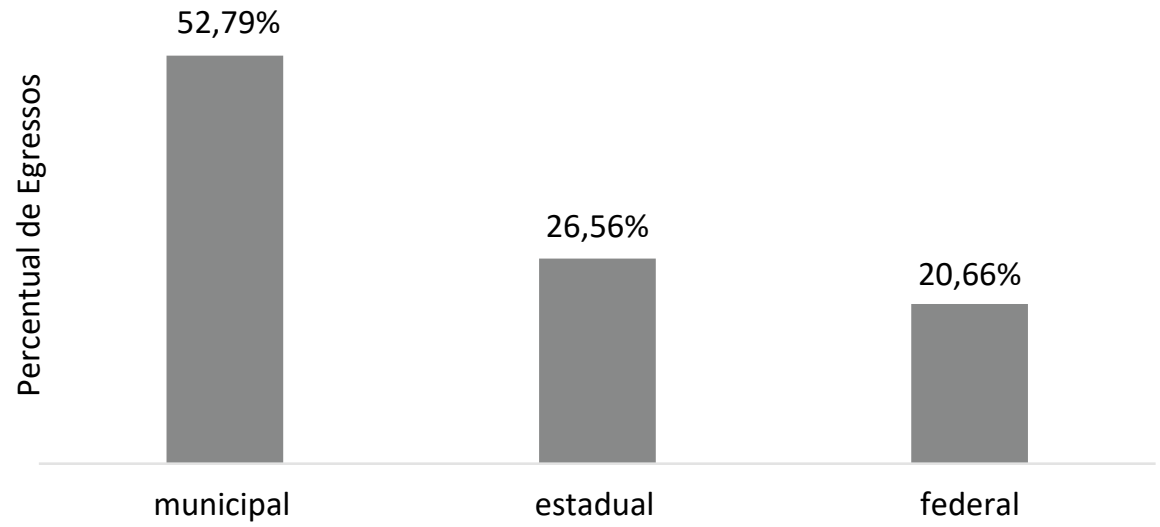

Fonte: BARROS, 2016 


\section{Grafico 6 - Tipo de vínculo ds egressos aprovados em concurso pós GPM}

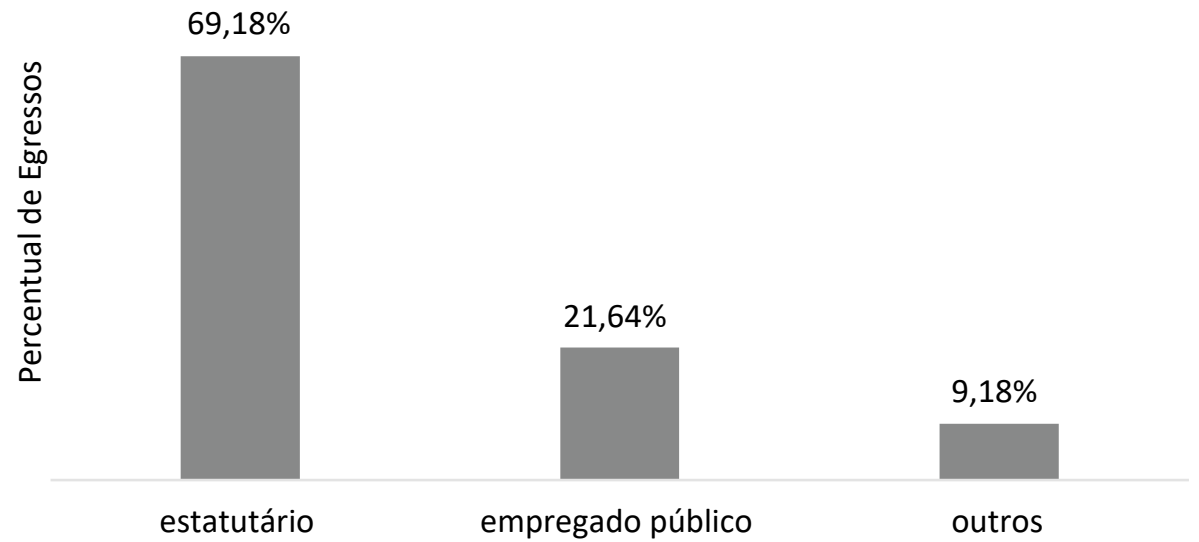

Fonte: BARROS, 2016

Em relação ao concurso público, vale ressaltar que, quando este foi instituído no Brasil (CF/34), não possuía valorização junto à população (ABRúcıo, 2007), mas foi ganhando importância no processo de evolução da administração pública brasileira, passando a ser obrigatório com a CF/88, instituindo de vez a seleção meritocrática e universal como regra. Assim, a aprovação em concurso é a maior medida de crescimento profissional no serviço público, pois é a única forma de ingresso em uma carreira pública.

A quantidade de egressos da amostra que ocupam cargos comissionados de chefia ou de assessoramento também se mostrou expressiva: $20,56 \%$ do total (Gráfico 7). Isso demonstra que a capacitação teve efeitos relevantes na preparação dos servidores para assumirem cargos de gestão, porque os critérios utilizados para decidir quem obterá cargo ou função são permeados de subjetividade e sabe-se que ainda há resquícios de patrimonialismo na administração pública brasileira. Por essas razões, nem sempre a capacitação, mesmo que em nível de pós-graduação, materializa-se em crescimento profissional daqueles que a fizeram, já que parte dos cargos ainda é ocupada usando fundamentos alheios à noção de meritocracia (IPEA, 2010). 


\section{Grafico 7 - Funções comissionadas no serviço público - pós GPM}

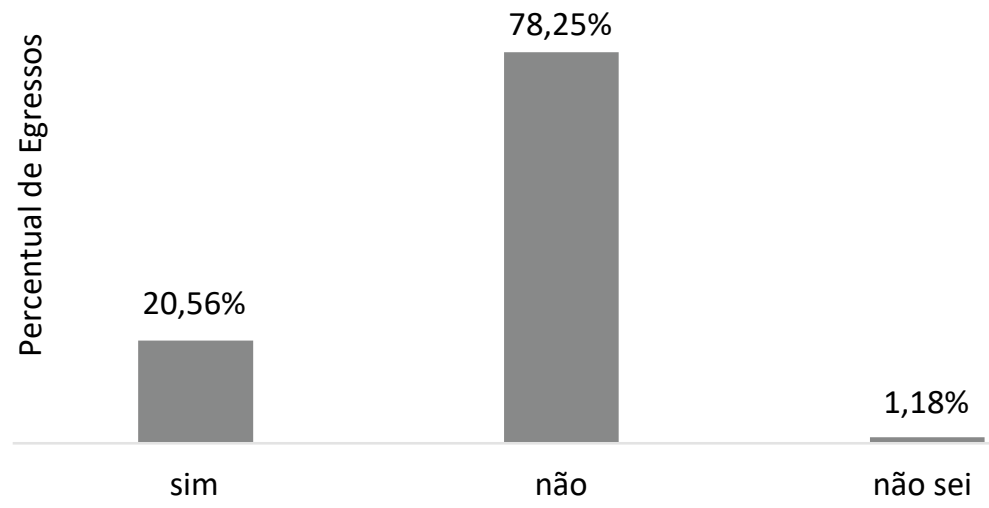

Fonte: BARROS, 2016

O número de servidores que foram cedidos a outros órgãos em razão de conhecimentos especializados obtidos no curso foi de 8,21\% (Gráfico 8). A razão disso pode ser que a cessão de servidores não é algo simples, pois depende da aprovação de várias instâncias e, em muitos casos, os órgãos não querem perder servidores para outros, ainda que visando ao benefício da administração como um todo. Mesmo assim, o número tem sua relevância, pois nos informa que, mesmo com todas as dificuldades existentes, $8,21 \%$ conseguiram um meio de colocar em prática o que aprenderam em seus cursos e foram reconhecidos por isso, pelo menos pelas pessoas dos órgãos para os quais foram cedidos. Posto isso, podese considerar que os efeitos palpáveis de crescimento profissional dos egressos da amostra observada foram bastantes substantivos. 


\section{Grafico 8 - Cessão de servidor público - pós GPM}

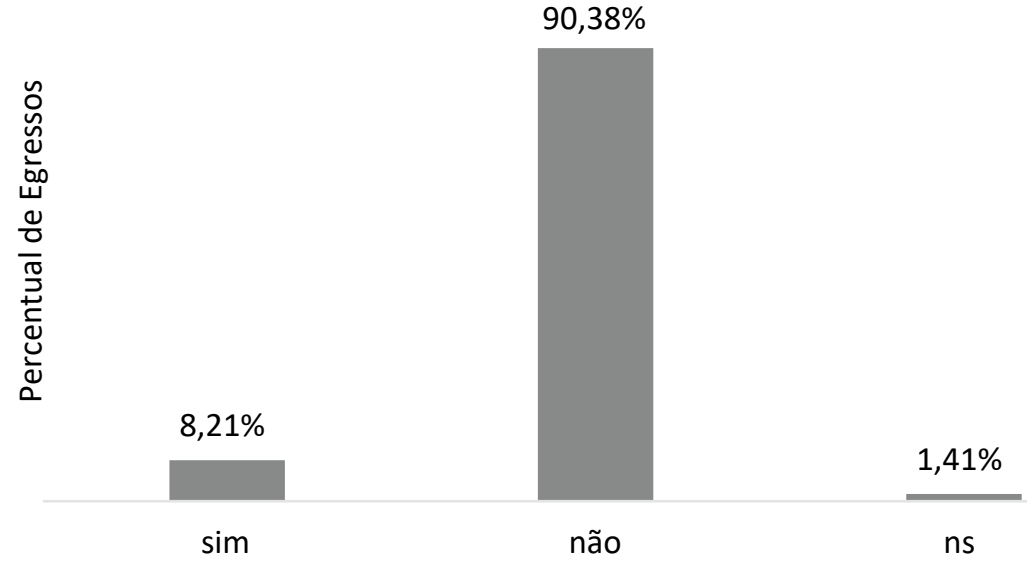

Fonte: BARROS, 2016

Outra forma objetiva de averiguar os efeitos positivos do curso GPM foi verificar se ele despertou nos egressos o interesse em aprimorar sua vida acadêmica, dada a importância de os servidores públicos buscarem constantemente se aperfeiçoar. O resultado foi que $27,07 \%$ dos egressos fizeram pelo menos outra pós-graduação após GPM (Gráfico 9), número que indica que o curso contribuiu para que os servidores buscassem crescimento acadêmico-profissional.

\section{Grafico 9 - Egressos que fizeram outra pós graduação após GPM}

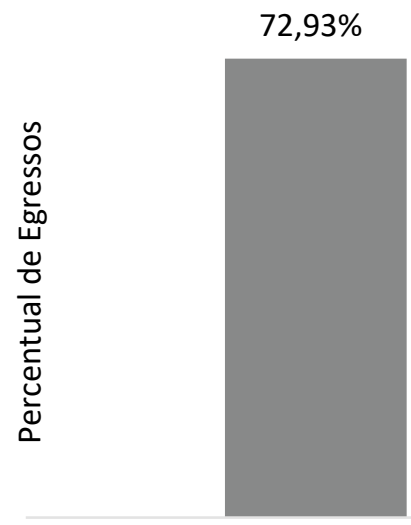

Não
$27,07 \%$

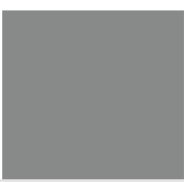

Sim

Fonte: BARROS, 2016

Em relaçãoàs variáveis que poderiam ter associação com essa dimensão, verificouse que há uma relação fraca, porém existente, entre as variáveis "tamanho do município" e "pós-graduação posterior à GPM". Essa relação advém da constatação de que as duas faixas que compreendem os maiores municípios possuem também a maior proporção de egressos que cursaram outra pós-graduação. Também no 
tocante à variável renda, a relação é fraca, pois, das cinco faixas de renda analisadas, quatro possuem proporções semelhantes; não obstante, a faixa de renda mais alta possui proporção bem menor do que as outras de egressos que cursaram outra pósgraduação após GMP.

Por fim, verificou-se que os egressos que já haviam feito alguma pósgraduação anterior à GPM foram os que proporcionalmente mais cresceram academicamente e que, nessa dimensão, a qualidade do curso não possui relevância, já que não há associação entre as duas variáveis analisadas, pois a proporção de egressos que fizeram outra pós-graduação é similar em todas as médias de qualidade do curso analisadas.

A dimensão de progressão na carreira é muito importante no contexto deste artigo, já que a estruturação das carreiras públicas é uma medida de fortalecimento das burocracias estatais, assim como a capacitação continuada dos servidores. Dessa forma, é importante aliar a progressão de carreira a fatores como capacitações formais, tal como são os cursos de pós-graduação, como meio de estimular o aprimoramento técnico dos servidores, ao passo que estrutura uma carreira sólida e com possibilidades de ascensão por meio de critérios objetivos. Como resultado, $25,81 \%$ dos egressos tiveram progressão em suas carreiras por terem concluído o curso (Gráfico 10). O número é significativo, mas poderia ser ainda maior.

Confrontando essa dimensão com as variáveis intervenientes, descobriu-se que há forte associação entre progressão salarial e ser servidor público antes de cursar GPM: identificou-se que quase a totalidade dos que progrediram na carreira (25,81\% dos egressos) já eram servidores públicos antes de começarem o curso. Essa realidade corrobora um argumento weberiano:

Segundo a experiência, o ótimo relativo para o êxito e manutenção de uma mecanização rigorosa do aparato burocrático é proporcionado por um salário monetário certo, conjugado à oportunidade de uma carreira que não dependa de simples acaso e arbítrio" (WEBER, 1982, p. 242). 


\section{Grafico 10 - Progressão na carreira - pós GPM}

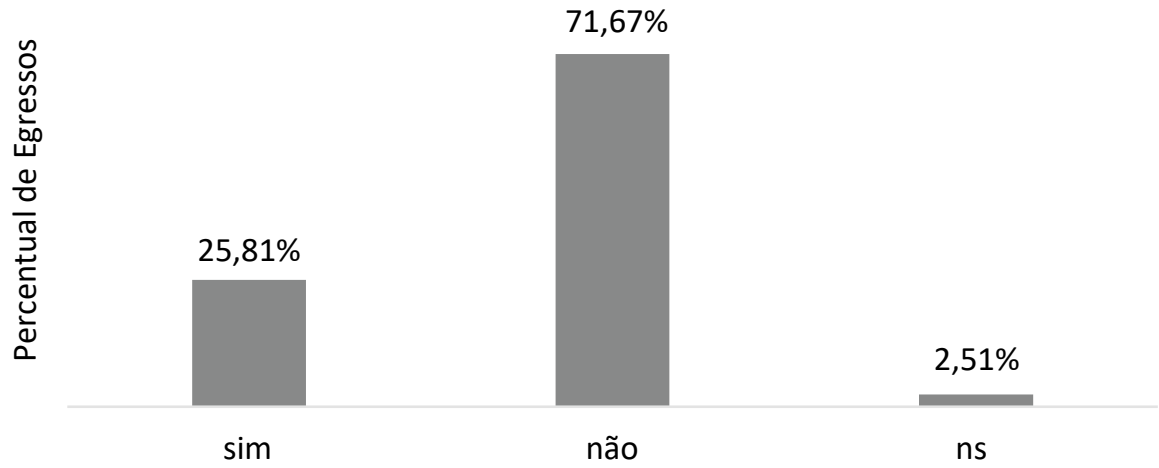

Fonte: BARROS, 2016

Assim, investir na estima do servidor se faz necessário, sendo que proporcionar um bom salário juntamente com uma boa carreira é imprescindível: "a segurança relativamente grande da renda do funcionário, bem como as recompensas em consideração social, fazem do cargo público uma posição muito ambicionada (...)" (WEBER, 1982, p. 237).

Entende-se, então, que os burocratas necessitam de reconhecimento social (primeiro de si próprio e dos que trabalham na mesma repartição pública que ele), mas também de receber bons salários. Estes devem ser estipulados dentro da noção de carreira que leve em conta o tempo de serviço e também as capacitações realizadas pelo servidor. A "posse de diplomas educacionais (...) está habitualmente ligada à qualificação para o cargo. Naturalmente, essas certidões ou diplomas fortalecem o "elemento estamental" na posição social do funcionário (WEBER, 1982, p. 233). Dessa forma, verificar se o egresso teve algum tipo de crescimento objetivo em razão de sua qualificação formal demonstra se os servidores públicos que realizaram o curso têm tido essa motivação, no sentido de saber que a capacitação os ajuda em seu crescimento profissional.

É relevante constatar que, em todas as dimensões verificadas, a maior parte dos egressos concordou ter havido efeitos positivos, ou seja, melhoria efetiva do desempenho profissional, maior reconhecimento dos egressos em seu trabalho, elevação da autoestima, nomeação a cargos de chefia e de confiança, aprovação em concursos públicos e progressão na carreira.

\section{As relações das variáveis intervenientes}

De forma geral, os números da pesquisa demostram também que a maior parte das variáveis intervenientes, que de acordo com a hipótese inicial influenciariam 
de alguma forma a percepção dos egressos do curso de GPM, mostraram-se pouco relevantes quando analisadas em comparação com as variáveis dependentes.

Esperava-se que a variável tamanho dos municípios tivesse grande influência nas dimensões estudadas, já que os pequenos municípios possuem maior dificuldade em implementar suas políticas públicas (ABRúcIO, 2007; CARVALHO, 2011; LASSANCE, 2013). O tamanho do município foi considerado em quatro dimensões de resultado e apenas se achou uma fraca relação com a variável de ter feito pós-graduação após GPM, já que o percentual de respondentes que continuaram a se capacitar foi maior nos municípios com mais de 100.000 habitantes.

Assim, percebe-se que aos pequenos e médios municípios também têm chegado oportunidades de capacitação, bem como maior possibilidade de desenvolvimento profissional. Infere-se também que devem ser realizados mais estudos sobre o atual panorama do perfil dos servidores municipais, pois, nos últimos anos, com a expansão do ensino a distância, pode ter havido uma melhora considerável no nível de qualificação desses servidores.

Historicamente, os servidores públicos mais bem preparados tinham sua concentração quase total no Distrito Federal (sejam servidores federais ou distritais). Essa é outra realidade que vem se alterando para melhor, pois mais de $50 \%$ dos egressos que responderam à pesquisa eram de servidores municipais, o que reforça os dados de Carvalho (2011) sobre o crescimento do funcionalismo público municipal no Brasil após a década de 70 do século passado.

Em relação à faixa etária, em termos gerais, ela não interfere de forma expressiva nas dimensões de resultados, mas apresentou algumas informações interessantes. A faixa etária dos egressos entre 61-70 anos se destacou em várias respostas, pois proporcionalmente foram os que mais concordaram que tiveram melhoria em seu desempenho profissional, mas também foram os que menos consideraram ter reconhecimento por parte de terceiros. Mesmo assim, também nessa faixa etária houve o maior número de pessoas cedidas para outros órgãos públicos e promovidas na iniciativa privada. Além disso, foram os egressos que, proporcionalmente, mais fizeram outra pós-graduação após GPM.

Observa-se então que essas pessoas, ainda que não percebam o reconhecimento no ambiente de trabalho, contribuem para os órgãos públicos e para o mercado em geral, pois ainda buscam se capacitar e percebem seu desempenho aumentar de forma prática. Destaca-se também que os mais jovens foram os que mais tiveram aprovação em concurso público, demonstrando que, para esses egressos, a especialização em GPM contribuiu em conhecimento teórico. Já os egressos da faixa-etária entre 31-40 se destacaram no quesito nomeações a cargos de chefia e assessoramento. Assim, percebe-se que a capacitação deve ser dirigida a todas as 
faixas etárias, pois em todas elas os alunos se apoderam do conhecimento, ainda que, dependendo da faixa-etária, os usos principais possam ser diferenciados. Deve, então, o Estado priorizar não somente os jovens ou os recém-admitidos no serviço público, mas todo o corpo de servidores.

A qualidade do curso de forma geral é um fator que contribuiu para explicar os resultados das três primeiras dimensões: melhoria do desempenho profissional, satisfação pessoal e crescimento profissional. Em todas elas, há uma forte associação entre as variáveis envolvidas, redundando em que, quanto melhor foi a avaliação do egresso em relação à qualidade média do curso, maior foi o grau de sua satisfação com seu desempenho profissional, com a sua confiança em si e com o reconhecimento de terceiros. O mesmo ocorreu com todos os aspectos do crescimento profissional. Já em relação ao crescimento acadêmico, a variável média da qualidade não se relaciona.

Reforça-se que a qualidade dos cursos em todos os aspectos é essencial para o atingimento dos resultados pretendidos, devendo em todo caso de educação profissional ser a qualidade ponto crucial a ser alcançado.

Outra questão objetiva perguntada aos egressos foi se eles já haviam cursado alguma outra pós-graduação antes de GPM. Verificando as relações dessa variável com as variáveis dependentes das dimensões analisadas, tem-se que ter realizado alguma pós-graduação anterior à GPM tem associação com a dimensão de crescimento acadêmico, já que o percentual de pessoas que fizeram uma pósgraduação depois de cursarem GPM foi maior entre os que já haviam feito uma pós-graduação anteriormente.

Significa, então, que as pessoas mais bem qualificadas são também aquelas mais interessadas em continuar se capacitando e aprendendo. Esse resultado é relevante, pois demonstra que, apesar de umas das justificativas da criação e relevância do curso de GPM ser de contribuir para a capacitação de mão de obra pouco capacitada, parte dos egressos já era bem qualificada e, a julgar pelos resultados obtidos na dimensão de crescimento acadêmico, há um círculo virtuoso entre pessoas bem qualificadas que procuram cada vez mais oportunidades de capacitação.

Quanto à área do curso de graduação do egresso, cruzou-se essa variável com a de melhoria de desempenho profissional, e o resultado é que, em geral, todas as áreas apresentam resultados parecidos e favoráveis, sendo que a área de Ciências Biológicas se destacou, já que $100 \%$ das pessoas com essa formação concordaram no total em ter tido melhoria em seu desempenho. Considerando que todo órgão público tem necessidade de possuir profissionais com conhecimentos de gestão pública, mas que muitos órgãos têm poucos cargos específicos para esse perfil, pode ser que esses egressos com formação em Biologia já padeciam com a falta de 
conhecimento nessa seara, podendo com a capacitação preencher essa lacuna em suas atividades profissionais.

A variável gênero tem forte relação com a elevação da confiança em si e uma relação mais fraca com o reconhecimento no trabalho, sendo que em ambas as maiores proporções de egressos foram homens. Dessa forma, percebe-se que os homens se sentem mais confiantes, em geral, com os conhecimentos apreendidos e possuem maior reconhecimento de terceiros também. Esse dado é interessante, pois, se, em relação à percepção da melhoria do desempenho, os números são praticamente idênticos, mas passam a diferir nas análises bivariadas feitas na dimensão de satisfação pessoal, isto significa que há um descompasso, no caso das mulheres, que acreditam que aprenderam tanto quanto os homens, mas não confiam em si como eles, nem se sentem reconhecidas da mesma forma. Portanto, é um alerta aos gestores que atuam na área de pessoal dos órgãos públicos, pois em muitas repartições ainda pode existir algum tipo de discriminação relacionada ao gênero.

Por sua vez, a renda familiar possui relação com algumas das variáveis dependentes estudadas. Em relação à dimensão satisfação pessoal, a renda familiar interferiu no reconhecimento de terceiros, sendo que entre os de mais baixa renda o percentual dos que concordam em ter havido maior reconhecimento no ambiente de trabalho é maior do que entre os de alta renda. Isso pode ser devido à possibilidade de que, para essas pessoas com menor renda, a pós-graduação feita influenciou positivamente no papel que possuíam em suas repartições, sendo mais respeitados, enquanto os de mais alta renda provavelmente já se sentiam ouvidos e considerados no ambiente de trabalho.

Houve também verificação de relação dessa variável com a nomeação em cargos de chefia ou cargos de confiança, sendo que os de renda mais alta tiveram maior proporção de nomeações. Aqui não há como definir relações de causalidade, mas uma hipótese é que a alta renda dessas pessoas já seja resultado dessas nomeações e não o contrário. De todo modo, há, sim, associação, como no caso do crescimento acadêmico. Entre os de maior renda foi menor o número dos que continuaram se capacitando, talvez porque justamente os que têm maior renda a possuam também por já ter alto nível de capacitação.

Pelo exposto, os resultados encontrados da pesquisa demonstram que o curso de GPM tem contribuído para o fortalecimento da burocracia pública, que, para Weber (1982) é o meio mais racional de organização possível, sendo que nessa forma os servidores públicos têm função ímpar. 


\section{Considerações finais e recomendações}

Este trabalho buscou verificar, por meio de pesquisa quantitativa, quais as percepções dos egressos em relação aos efeitos do curso de especialização em Gestão Pública Municipal. O questionário apresentado aos egressos e as análises e informações obtidas por meio dele se apresentam sob uma forma de avaliação dessa ação governamental consubstanciada na oferta desse curso de pós-graduação aos servidores públicos. O quantitativo de egressos que participou da pesquisa foi expressivo, indicando a consciência que eles possuem a respeito da importância de se avaliar as políticas públicas, ainda que estas estejam em implementação, como é o caso de GPM.

Conclui-se, de acordo com as percepções e informações prestadas, que essa pósgraduação tem tido efeitos expressivos em termos profissionais e acadêmicos para os egressos do curso, afetando não só aos estudantes, mas à realidade profissional e social que os cerca. Assim, os resultados referentes às cinco dimensões aqui estudadas fortalecem o argumento de que o Estado brasileiro - assim como praticamente toda a comunidade internacional - enxerga que a qualificação atrelada a uma boa carreira são uma forma de o Estado manter servidores qualificados em seus quadros funcionais. Deve haver mecanismos diversos para estimular que os servidores se capacitem (RICUPERO, 2015; WEBER, 1982).

Salienta-se também o esforço da União em coordenar uma espécie de cooperação entre ela própria, os municípios e estados, conseguindo que o curso tenha tido um alcance considerável em todas as regiões do país (20 estados), por meio de instituições públicas de ensino superior (40) e dos polos de apoio presencial (256).

Por fim, percebe-se que o Estado brasileiro tem avançado em termos de administração pública, pois, ao mesmo tempo em que impõe esforços para qualificar seu corpo burocrático, também tem buscado se modernizar em suas formas de atuação. Nesse sentido, recomenda-se que sejam feitas avaliações sobre outros aspectos do curso que este estudo não adentrou, como de viabilidade econômica e avaliação de impacto nos municípios alcançados pela política. 


\section{Referências bibliográficas}

ABRÚcio, F. L. Trajetória recente da gestão pública brasileira: um balanço crítico e a renovação da agenda de reformas. Rev. Adm. Pública, Rio de Janeiro, v. 41, p. 67-86, 2007.

BARros, S.G.G.G. Capacitação de servidores públicos municipais: a visão dos egressos do curso de Gestão Pública Municipal (UAB). Dissertação (mestrado) Instituto de Pesquisa Econômica Aplicada, Programa de Pós-Graduação em Políticas Públicas e Desenvolvimento. Brasília, Ipea, 2016.

BRASIL. Constituição (1988). Disponível em <http://www.planalto.gov.br/ccivil_03/ Constituicao/Constituicao.htm> Acesso em: 5 jan. 2016.

. Decreto no 5.800, de 8 de junho de 2006. Dispõe sobre o Sistema Universidade Aberta do Brasil. Disponível em: <http://www.uab.capes.gov.br/ images/stories/downloads/legislacao/decreto5800.pdf>. Acesso em: 31 mar. 2014.

BATISTA, Mariana. Burocracia local e qualidade da implementação de políticas descentralizadas: uma análise da gestão de recursos federais pelos municípios brasileiros. Revista do Serviço Público, v. 66, p. 345-370, 2015.

BERSCH, K; PRAÇA, S; TAYLOR, M. State capacity and bureaucratic autonomy within national States: mapping the archipelago of excellence in Brazil. In: Latin American Studies Association Conference. Washington. Disponível em http://cepesp. files. wordpress. com/2013/06/bersch-praca-taylor-state-capacity-and-autonomymay-1_lasa. pdf. 2013.

Coordenação de Aperfeiçoamento de Pessoal de Nível Superior (Capes). Apresentação DED - Programa Nacional de Administração Pública (Pnap). Brasília, 2013.

. Edital n¹, de 27/04/2009. A Capes torna público às Instituições Públicas de Ensino Superior- Ipes participantes do Sistema Universidade Aberta do Brasil UAB, o Programa Nacional de Formação em Administração Pública - Pnap. Brasília, 2009. Disponível em < em http://www.capes.gov.br/images/stories/download/ bolsas/EDITAL_N1_PNAP_DED_CAPES_2009.pdf>Acesso em 06 set. 2015.

Carvalho, D. E. Emprego Público e ocupações por município. In: Cardoso, José Celso. Burocracia e ocupação no setor público brasileiro. Série Diálogos para o Desenvolvimento, v. 5. Ipea: Rio de Janeiro, 2011. Cap. 7.

Cervo, A. L. O Parlamento Brasileiro e as Relações Exteriores (1826 - 1889). Brasília: Editora Universidade de Brasília, 1981.

EVANS, P.; RAUCH, E. J. Burocracia e crescimento: uma análise internacional dos efeitos das estruturas do Estado "weberiano" sobre o crescimento econômico. Revista do Serviço Público, v. 65, n. 4 p. 407-437, out/dez. Brasília, 2014.

FREITAS, I. V. B. et al. Avaliação de políticas públicas no Senado Federal. Brasília; SEEP/Senado Federal, 2013.

Gerahardt, E.; SilveirA, D. T (orgs). Métodos de pesquisa. Porto Alegre: editora da UFRGS, 2009. 
Instituto BRAsileiro de Geografia e Estatística (IBGE). Pesquisa de Informações Básicas Municipais - Munic. Perfil dos estados e dos municípios brasileiros: 2014. Coordenação de população e indicadores sociais. - Rio de Janeiro, 2015. Disponível em <http://downloads.ibge.gov.br/downloads_top.php>. Acesso em 02 fev. 2016. INSTITUTO DE PESQUISA ECONÔMICA APLICADA (IPEA). Estado, instituições e democracia: república. Livro 9, vol. 1 (Série: Eixos Estratégicos do Desenvolvimento. Projeto: Perspectivas do Desenvolvimento Brasileiro). Rio de Janeiro, 2010.

LASSANCE, A. Federalismo no Brasil: trajetória institucional e alternativas para um novo patamar de construção do Estado. In: LINHARES, Paulo de Tarso; CRONEMBERGER, C.; LASSANCE, A. (organizadores). Federalismo à Brasileira: questões para discussão. Brasília/Rio de Janeiro: Ipea, 2013.

MotTA, F. C. P. O que é burocracia? São Paulo: Brasiliense, 2008.

PILATI, R; PORTO, J. B; SILVINO, A.M.D. Validação de medidas de efetividade de cursos de mestrado e doutorado no trabalho. Revista de Psicologia Organizacional e do Trabalho, Florianópolis, v. 7. n. 2, dez. 2007.

RICUPERO, R. Profissionalização do servidor público: requisito para o desenvolvimento. Revista do Serviço Público, v. 45, n. 2, p. 149-153, 2015.

Weber, M. Conceitos Básicos de Sociologia. São Paulo, Centauro, 2002. 5a edição. Economia e sociedade: fundamentos da Sociologia Compreensiva. v. 2.

Brasília/DF: Editora da Universidade de Brasília. São Paulo: Ed. Impressa Oficial do Estado de São Paulo, 2004.

. Ensaios de Sociologia. 5ạ edição, Editora LTC, Rio de Janeiro, 1982.

\section{Simone Guimarães Guerra Gama Barros}

Fundação CAPES. Mestre em Políticas Públicas e Desenvolvimento pelo Instituto de Pesquisa Econômica Aplicada. Doutoranda em Educação em Ciências Química da Vida e Saúde pela Universidade Federal do Rio Grande do Sul. 